\section{Opportunity Evaluation and Implementation}

\section{Providing strategic energy solutions through thoughtful planning and practical know-how to produce groundbreaking results}

\section{NREL Guides Integrated Energy Planning and Focused Solutions}

The National Renewable Energy Laboratory (NREL) is the U.S. Department of Energy's (DOE's) only national laboratory focused on renewable energy and energy efficiency. For more than 35 years, our energy research, development, analysis, commercialization, and deployment work with public and private sector partners around the world has catalyzed the expansion of global clean energy solutions.

Through the combined expertise of our NREL research staff and our external industry relationships, our team works with clients and stakeholders to define and meet their energy goals by providing proven technical assistance, policy expertise, and education. We have experience providing solutions to energy challenges encountered by national, state, and local agencies; private-sector businesses; and partners in more than 30 countries.

Complex, new or large energy initiatives require integrated planning and decision-making that draws on a deep knowledge of energy technologies, an objective evaluation of alternatives, and the capability to engage complex stakeholders. NREL's Opportunity Evaluation and Implementation (OE\&I) group provides this expertise through a unique combination of skills including broad technical knowledge across multiple renewable energy technologies, an understanding of markets and policies, and an ability to work effectively with customers to define and understand their implementation needs.

\section{Examples of Our Work}

Federal Emergency Management Agency (FEMA). As a core member of the FEMA energy technical assistance team, we support disaster recovery efforts such as long-term, on-site support in New York and New Jersey following Hurricane Sandy. We identify opportunities to rebuild better, incorporate sustainability measures during recovery, identify opportunities for workforce development, and create a more resilient infrastructure system to protect against future disasters.

\section{We provide:}

- Excellence in program leadership, management, and control for interdisciplinary and multi-stakeholder projects

- Strategic planning for federal agencies and other governmental entities including target setting, performance measurement, scenario analysis, and tracking and reporting

- Coordination of strategic energy policy and economic analysis expertise to provide detailed technology implementation guidance on grid integration, building efficiency, renewable fuels, and transportation solutions

- Custom designed solutions for disaster preparation and recovery, island nations, remote communities, and other unique energy challenges and environments

- Education, training, and workforce development to build capacity for energy dependence
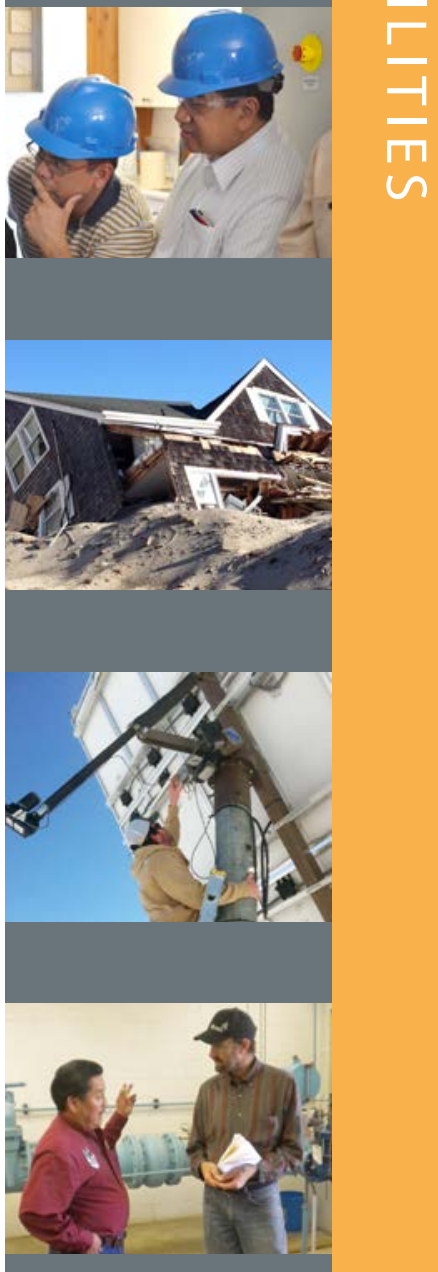

We offer "technology neutral" guidance utilizing

NREL's entire suite of decision-support tools and processes to help clients in regions, communities, campuses, buildings, and facilities address energy and environmental goals. Our goal is to move viable clean energy solutions out of the lab and into the market by helping our clients achieve triple bottom-line successes in energy, economy, and the environment. 
NREL's capabilities encompass the

laboratory's full range of technologies,

which span the energy efficiency and

renewable energy spectrum. NREL

is internationally recognized as a

technology innovator and a leader in

advancing renewable energy and energy

efficiency. Let NREL help propel your

organization toward a more sustainable energy future.

Under DOE's Office of Indian Energy - START program, NREL is working in western Alaska with the Native Village of Kongiganak and Intelligent Energy Systems to reduce diesel fuel use and optimize wind power to provide both electricity and heat to the community, including at its new school. Photo by Connie Fredenberg, Marsh Creek.

\section{Office of Indian Energy - Strategic Technical Assistance Response Team} (START) Program. We provide expertise and management for DOE's of Indian Energy - START program, working with tribal entities and Alaskan Native villages to implement efficiency and renewable projects that are a catalyst for community development.

\section{Hawaii Clean Energy Initiative}

(HCEI). HCEI is an historic agreement between the state of Hawaii and DOE to achieve $70 \%$ clean energy by 2030 .

The HCEI is a public-private partnership engaging local stakeholders to establish clean energy goals and commitments implemented through technology deployment projects in electricity generation, transportation, energy efficiency, and renewable fuels. HCEI successes are applicable to island nations or regions with islanded grids.

\section{The Clean Energy Solutions Center}

(CESC). Our team helps governments, advisors, and analysts create policies and programs that advance the deployment of clean energy technologies. Since December 2012, CESC experts have responded to more than 90 requests for expert assistance submitted by policymakers and government-affiliated organizations around the world. In addition, more than 4,000 participants have taken part in CESC trainings offered through webinars, videos, and other resources.

\section{Enhanced Capacity for Low Emission Development Strategies (EC-LEDS):}

NREL provides a program management function as well as in-depth clean energy technical assistance for a U.S. government program that supports partner countries in their pursuit of economic growth while slowing the pace of greenhouse gas emissions.
For more information about NREL's strategic, clean energy planning and integrated solutions services, visit our website at www.nrel.gov/tech_deployment/.

To learn more, contact

Sheila.Hayter@nrel.gov

National Renewable Energy Laboratory 15013 Denver West Parkway

Golden, C0 80401

303-275-3000 • www.nrel.gov

NREL is a national laboratory of the U.S. Department of Energy, Office of Energy Efficiency and Renewable Energy, operated by the Alliance for Sustainable Energy, LLC.

NREL/FS-7A40-60472 • 0ctober 2013

Front page photography (from the top): iStock 23956661; Dan Bilello, NREL 26953; Eliza Hotchkiss, NREL; Karen Peterson, NREL 20893; Colton Heaps, NREL 23642

Printed with a renewable-source ink on paper containing at least $50 \%$ wastepaper, including $10 \%$ post consumer waste. 